\title{
ВПЛИВ СПІВВІДНОШЕННЯ МІЖ ІНОКУЛЯТОМ І ОРГАНІЧНИМ СУБСТРАТОМ НА ВИХІД БІОГАЗУ
}

Г.О. Четверик, канд. техн. наук, Н.О. Маслова

Інститут відновлюваної енергетики НАН України, 02094, вул. Гната Хоткевича, 20А, м. Київ, Україна.

Визначення метанового потенціалу органічних субстратів є важливим завданням на етапі проєктування біогазових комплексів, заводів або станцій. Вихідні субстрати, особливо иче стосується субстратів, які складаються з посліду або гною, відрізняються своїм складом протягом року. Тому на біогазових об'єктах зазвичай створюють лабораторії, де перевіряють характеристики вихідного субстрату й виконують тести з визначення його метанового потенщіалу. Метою роботи є дослідження виходу біогазу залежно від співвідношення між інокулятом і субстратом. Наведено умову, за якої значення співвідношення між інокулятом і субстратом можна вважати раціональним, а саме: необхідно, щэоб відхилення значення виходу біогазу було незначним відносно невеликих змін співвідношення між інокулятом $і$ субстратом. Наведено результати експериментів з метанової анаеробної переробки коров'ячого гною при різних значеннях співвідношення між інокулятом і коров'ячим гноєм. Визначено вихід та склад біогазу, ступінь переробки органічної речовини. Встановлено раціональне значення співвідношення між інокулятом і коров'ячим гноєм. Проаналізовано необхідність перемішування субстрату при виконанні тесту з визначення метанового потенціалу в лабораторних умовах. 3'ясовано, щзо для органічних субстратів, які легко зброджуються або досить розбавлені водою, достатньо струшувати вміст реактора вручну раз на добу. У разі, якщо у складі органічного субстрату переважають компоненти, що важко зброджуються або органічний субстрат містить високу кількість сухої речовини, перемішування обов'язкове. Наведено спосіб перемішування для проведення тесту з визначення метанового потенціалу органічних субстратів, які містять коров'ячий гній. Наведено два критерії, згідно з якими слід виконувати вибір співвідношення між інокулятом і досліджуваним субстратом для різних видів органічних субстратів при визначенні їхнього метанового потенціалу: перший критерій - це наявність власної клітинної біомаси в субстраті; другий критерій - ие наявність переважно легко зброджуваних компонентів у субстраті. Рекомендовано необхідні значення співвідношення між інокулятом $і$ досліджуваним субстратом для органічних субстратів, що є перспективними $i$ можуть першочергово бути використані в біогазових станціях. Бібл. 20, табл. 3, рис. 1.

Ключові слова: біогаз, метановий потенціал, органічні субстрати, інокулят, зброджування. 


\title{
INFLUENCE OF RATIO BETWEEN INOCULUM AND ORGANIC SUBSTRATE ON THE YIELD OF BIOGAS
}

\author{
H. Chetveryk, cand. of technical science, N. Maslova
}

Institute of Renewable Energy of the National Academy of Sciences of Ukraine, 02094, 20A Hnata Khotkevycha St., Kyiv, Ukraine.

Determining a methane potential of organic substrates is an important task at the design stage of biogas complex, plants or stations. The raw substrates differ in their composition throughout the year especially those that contain droppings or manure. Therefore laboratories are usually set up at biogas plants to check the characteristics of the raw substrate and perform test to determine its methane potential. The aim of the work is to research the yield of biogas depending on the ratio between the inoculum and the substrate. The condition under which the value of the ratio between inoculum and substrate can be considered rational is given, namely: it is necessary that the deviation of the value of biogas yield was insignificant relative to small changes in the ratio between inoculum and substrate. The results of experiments on methane anaerobic conversion of cow manure at different values of the ratio between inoculum and cow manure are presented. The yield and composition of biogas and the degree of degradation of volatile solids have been determined. The optimal value of the ratio between the inoculum and the cow manure has been determined. The necessity of substrate mixing during methane potential test in laboratory conditions was analyzed. It has been found that for organic substrates that are easily digested or sufficiently diluted with water, it is sufficient to shake the contents of the reactor manually once a day. If the organic substrate is composed of components that are difficult to digest or the organic substrate contains a high amount of dry matter, mixing is mandatory. The mixing method for the test for methane potential of organic substrates containing cow manure is given. There are two criteria according to which the choice of the ratio between the inoculum and the substrate for different types of organic substrates when determining their methane potential should be performed: the first criterion is the presence of its own cell biomass in the substrate; the second criterion is the presence of mostly easily fermentable components in the substrate. The required values of the ratio between the inoculum and the substrate are recommended for organic substrates that are promising and can be primarily used in biogas plants. Bibl. 20, table 3, fig. 1 .

Keywords: biogas, methane potential, organic substrate, inoculum, digestion.

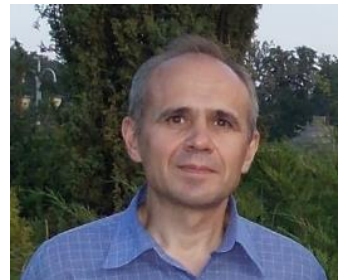

Г.О. Четверик
H. Chetveryk
Відомості про автора: старший науковий співробітник Інституту відновлюваної енергетики НАН України, кандидат технічних наук (2019 рік)

Освіта: Київський Національний Університет імені Тараса Шевченко, механікоматематичний факультет

Наукова сфера: біогаз, переробка органічних відходів

Публікації: 52 наукових публікацій, у тому числі 3 патенти

ORCID: 0000-0001-9398-1968

Контакти: тел./факс: +38 (044) 206-28-09

e-mail: biomassa@ukr.net
Author information: Institute of Renewable Energy of NAS of Ukraine, senior researcher. $\mathrm{PhD}$ since 2019 year

Education: Taras Shevchenko National

University of Kyiv, Faculty of Mechanics and Mathematics

Research area: biogas, organic waste utilization Publications: 52 scientific publications, including 3 patents

ORCID: 0000-0001-9398-1968

Contacts: tel./fax: +38 (044) 206-28-09

e-mail: biomassa@ukr.net 


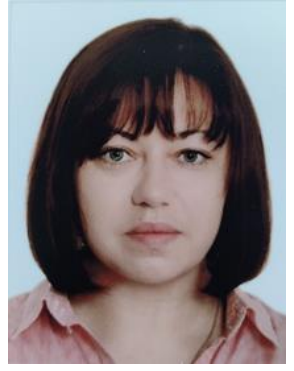

Н.О. Маслова N. Maslova
Відомості про автора: молодший науковий співробітник Інституту відновлюваної енергетики НАН України

Освіта: Київський Національний Університет імені Тараса Шевченка, хімічний факультет Наукова сфера: переробка органічних відходів

Публікації: 16

ORCID: 0000-0003-1465-1886

Контакти: тел./факс: +38 (044) 206-28-09

e-mail: biomassa@ukr.net
Author information: Institute of Renewable Energy of NAS of Ukraine, researcher

Education: Taras Shevchenko National University of Kyiv, Faculty of Chemistry Research area: utilization of organic waste Publications: 16

ORCID: 0000-0003-1465-1886

Contacts: tel./fax: +38 (044) 206-28-09

e-mail: biomassa@ukr.net
Вступ. Переробка посліду, гною, бурякового жому, рослинної біомаси, органічної складової побутових відходів методом метанового зброджування з отриманням біогазу $є$ перспективною. Постійно проводиться пошук нових видів біогазової сировини та розроблення нових методів інтенсифікації процесу зброджування. Сумісне зброджування різних видів сировини, особливо 3 використанням рослинної біомаси, дає змогу значно підвищити інтенсивність виходу біогазу.

Визначення метанового потенціалу органічних субстратів є важливим завданням на етапі проєктування біогазових комплексів, заводів або станцій. Отримані експериментальні результати використовують для оптимізації показників процесу зброджування, при яких спостерігається максимальний і стабільний вихід біогазу, та для прогнозування матеріальних балансів процесу зброджування.

Постановка завдання. Відомо, що для досягнення максимальної інтенсивності процесу зброджування органічні субстрати змішують 3 інокулятом. Одним із чинників, який суттєво впливає на перебіг та інтенсивність бродіння, $є$ співвідношення між органічною речовиною інокуляту та органічною речовиною досліджуваного субстрату (I/C). С. Ешхор
M. Miax та М. Гаворскі показали, що високе значення I/C приводить до швидкого $\mathrm{i}$ стабільного зброджування, але до менш послідовних результатів і $є$ ризик того, що утвориться менше біогазу з субстрату, ніж 3 інокуляту [1-3]. І. Ангелідакі, Ж. Ліндмарк та I. Перколіні показали, що низьке значення I/C приводить до інгібування процесу зброджування проміжними продуктами [4-6]. Зважаючи на відмінності перебігу процесу бродіння за різних значень I/C, важливим завданням $\epsilon$ визначення його раціонального значення.

Для визначення метанового потенціалу органічних субстратів зазвичай користуються протоколом експерименту, що відповідає вимогам міжнародних стандартів $[7,8]$, американських стандартів $[9,10]$, німецькому стандарту [11] або рекомендаціям, наведеним для роботи 3 автоматизованою системою визначення біогазового потенціалу субстратів [12]. 3 огляду на широкі межі діапазону варіювання значення I/C, наведених у вимогах до тесту з визначення метанового потенціалу [7-12], було поставлено завдання дослідити інтенсивність процесу зброджування залежно від співвідношення між органічною речовиною інокуляту і субстрату для коров'ячого гною - сировини, що переважно використовують у біогазових станціях. 
Метою роботи $\epsilon$ дослідження виходу біогазу залежно від співвідношення між інокулятом i субстратом. Для досягнення поставленої мети визначені такі завдання:

1. Провести експерименти щодо зброджування коров'ячого гною при різних значеннях співвідношення між інокулятом i субстратом.

2. Проаналізувати необхідність перемішування субстрату при виконанні тесту 3 визначення метанового потенціалу коров'ячого гною.

3. Навести критерії, згідно 3 якими слід виконувати вибір співвідношення між інокулятом i досліджуваним субстратом для різних видів органічних субстратів.

4. Надати рекомендації стосовно значення співвідношення між інокулятом і досліджуваним субстратом для проведення тесту з визначення метанового потенціалу для тих видів органічних субстратів, які $\epsilon$ перспективними $і$ можуть першочергово бути використані в біогазових станціях.

Вихід біогазу залежно від співвідношення між інокулятом i коров'ячим гноєм. У відділі відновлюваних органічних енергоносіїв Інституту відновлюваної енергетики НАН України були проведені експериментальні дослідження 3 метою вивчення впливу співвідношення між органічною речовиною інокуляту та коров'ячого гною на вихід біогазу.
Переробку субстрату виконували на лабораторній біогазовій установці, схему якої наведено в роботі [13].

Лабораторна біогазова установка

складається 3 наповненого водою теплоізольованого термостату, в якому розміщені реактори. Нагрівання i контроль температури води в термостаті здійснювали за допомогою електричного нагрівача 3 терморегулятором. Реактори герметично з'єднані з газгольдерами. Нерухома частина газгольдерів виставлена горизонтально і заповнена розчином $\mathrm{NaCl}$ для запобігання розчинення вуглекислого газу у воді. На рухомій частині газгольдерів нанесено відмітки для візуального визначення об'єму виробленого біогазу.

Для створення анаеробних умов всередині реактора газовий простір системи реакторгазгольдер безпосередньо перед початком експерименту продували азотом, об'єм якого втричі перевищував об'єм вказаного газового простору.

Для підготовки органічних субстратів були використані такі матеріали: коров'ячий гній, дистильована вода та інокулят, який попередньо був адаптований до схожих умов зброджування.

Вміст сухої речовини (СР) в гної та інокуляті і вміст золи в СР визначали методами, які описані в стандартах [14] і [15] відповідно, отримані результати наведено в табл. 1 . 
Таблиця 1. Характеристики інокуляту та коров'ячого гною

Table 1. Solids and ash value in the inoculum and cow manure

\begin{tabular}{|c|c|c|}
\hline \multirow{2}{*}{$\begin{array}{c}\text { Компонент } \\
\text { органічного субстрату }\end{array}$} & Вміст СР, \% & Вмараст золи в СР, \% \\
\cline { 2 - 3 } & 2,0 & 29,0 \\
Інокулят & 18,5 & 15,8 \\
\hline Коров'ячий гній & \multicolumn{2}{|c|}{ Весики } \\
\hline
\end{tabular}

Об'єм реакторів становив 1,5 дм $^{3}$, робочий об'єм реакторів $\mathrm{V}_{\mathrm{p}}$ становив 1,05 дм³ $^{3}$.

Експерименти проведено в мезофільному режимі при температурі $35^{\circ} \mathrm{C}$. Було підготовлено чотири субстрати, значення I/C в яких: $\mathrm{I} / \mathrm{C}=0$; $\mathrm{I} / \mathrm{C}=1 ; \mathrm{I} / \mathrm{C}=2 ; \mathrm{I} / \mathrm{C}=4$. Для розрахунку кількості компонентів (інокуляту та коров'ячого гною) в органічних субстратах розв'язували таку систему рівнянь [12]:

$$
\begin{gathered}
\mathrm{m}_{\mathrm{I}} \cdot \mathrm{VS}_{\mathrm{I}} \cdot \rho_{\mathrm{I}}+\mathrm{m}_{\mathrm{S}} \cdot \mathrm{VS}_{\mathrm{S}} \cdot \rho_{\mathrm{S}}=\mathrm{V}_{\mathrm{p}}, \\
\mathrm{m}_{\mathrm{I}}: \mathrm{m}_{\mathrm{S}}=\mathrm{I} / \mathrm{C},
\end{gathered}
$$

де: $\mathrm{m}_{\mathrm{I}}$ - вага СОР інокуляту на початок процесу зброджування, г; $\mathrm{m}_{\mathrm{S}}$ - вага СОР досліджуваного субстрату на кінець процесу зброджування, г; $\mathrm{VS}_{\mathrm{I}}$ - частка COP у вихідному інокуляті; $\mathrm{VS}_{\mathrm{S}}$ - частка COP у досліджуваному субстраті; $\rho_{\mathrm{I}}-$ густина інокуляту, г/дм ${ }^{3} ; \rho_{\mathrm{S}}-$ густина досліджуваного субстрату, г/дм³.

В табл. 2 наведено дані щодо початкового вмісту сухої органічної речовини $\left(\mathrm{COP}_{\mathrm{cв}}\right)$ в інокуляті та в коров'ячому гної для підготовлених субстратів.

Таблиця 2. Початковий вміст СОР св у вихідних субстратах

Table 2. Initial $\mathrm{VS}_{\text {ad }}$ value in the raw substrate

\begin{tabular}{|c|c|c|}
\hline \multirow{2}{*}{$\begin{array}{c}\text { Значення } \\
\text { I/C }\end{array}$} & \multicolumn{2}{|c|}{ Вміст СОР, у тому числі: } \\
\cline { 2 - 3 } & в інокуляті, г/дм ${ }^{3}$ & в коров'ячому гної, г/дм ${ }^{3}$ \\
\hline 0 & 0 & 13,7 \\
2 & 13,7 & 13,7 \\
4 & 14,2 & 7,1 \\
& 14,4 & 3,6 \\
\hline
\end{tabular}

Наведемо аналіз необхідності виробленого біогазу через шар субстрату без перемішування субстрату при виконанні тесту з перешкод.

визначення метанового потенціалу.

Перемішування субстрату сприяе покращенню ефективності процесу бродіння. Розпад переважної більшості органічних субстратів не залежить від перемішування, оскільки воно лише сприяє проходженню
Для проведення тесту 3 визначення метанового потенціалу органічних субстратів використовують різні способи перемішування субстрату, а саме ручне струшування, мішалки, що приводяться в дію приводними двигунами, магнітні мішалки. 
Вміст вологи у підготовлених субстратах становить 96-97\%. При цьому вміст органічної речовини у субстраті становить $30-40 \%$ його оптимального значення. В. Ванг, Ф. Рапосо, К. Холігер, І. Пеколіні показали, що для органічних субстратів, які досить розбавлені водою достатньо струшувати вміст реактора вручну раз на добу [6, 16-18].

Таким чином, показано, що для проведення тесту 3 визначення метанового потенціалу органічних субстратів, що містять коров'ячий гній, достатньо струшувати вміст реактора вручну раз на добу, як і для органічних субстратів, які переважно містять компоненти, що легко зброджуються. Для органічних субстратів, у складі яких переважають компоненти, що важко зброджуються або вони містять високу кількість сухої речовини, перемішування обов'язкове. Інтенсивність перемішування зазвичай залежить від в'язкості середовища, на яку в першу чергу впливають компонентний склад органічного субстрату та вміст сухої речовини. Тому кількість перемішувань за добу та кількість обертів мішалки необхідно підбирати залежно від компонентного складу органічного субстрату та вмісту сухої речовини.

У процесі експериментів визначали такі показники: вологість та зольність збродженої маси, об’єм виробленого біогазу, об’ємну концентрацію метану та вуглекислого газу в біогазі, ступінь розкладу сухої органічної речовини.

Вологість та зольність збродженої маси визначали методами, які описані в стандартах [14] і [15] відповідно.
Об’ємну концентрацію вуглекислого газу в біогазі $\mathrm{C}_{\mathrm{CO}_{2}}$ визначали 3 використанням газоаналізатора «ГХЛ». Об’ємну концентрацію метану в біогазі $\mathrm{C}_{\mathrm{CH}_{4}}$ визначали, припускаючи,

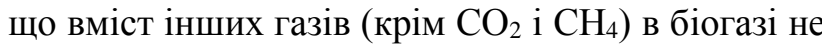
перевищував 2 \%, за залежністю [13]:

$$
\mathrm{C}_{\mathrm{CH}_{4}}=98 \%-\mathrm{C}_{\mathrm{CO}_{2}} \text {. }
$$

Ступінь розкладу $\kappa_{\mathrm{COP}}$ органічної речовини визначали за залежністю [12]

$$
\kappa_{\mathrm{COP}}=\frac{\mathrm{m}_{\mathrm{COP}, \Pi}-\mathrm{m}_{\mathrm{COP}, \mathrm{\kappa}}}{\mathrm{m}_{\mathrm{COP}, \Pi}} \cdot 100 \%,
$$

де: $\mathrm{m}_{\mathrm{COP}, п}$ - вага СОР на початку процесу зброджування, $г ; \mathrm{m}_{\mathrm{COP}, \mathrm{\kappa}}-$ вага $\mathrm{COP}$ в кінці процесу зброджування, г.

Під час виконання тесту 3 визначення метанового потенціалу органічних субстратів також отримують динаміку виходу біогазу. Кумулятивний вихід біогазу $\mathrm{Y}_{\text {Бг }}$ обчислювали в перерахунку на одиницю сухої органічної речовини досліджуваного субстрату за залежністю [13]:

$$
\mathrm{Y}_{\text {БГ }}\left(\tau_{\mathrm{n}}\right)=\sum_{\mathrm{i}=1}^{\mathrm{i}=\mathrm{n}} \mathrm{V}_{\text {БГ }}\left(\tau_{\mathrm{i}}\right)
$$

де: $\mathrm{n}$ - кількість показників за період зброджування; $\mathrm{V}_{\text {БГ }}\left(\tau_{\mathrm{i}}\right)$ - об'єм біогазу для i-го зняття показників, дм³. Об'єм виробленого біогазу визначали візуальним методом та приводили до нормальних умов.

На рис. 1 показано вихід біогазу для різних значень I/C. 


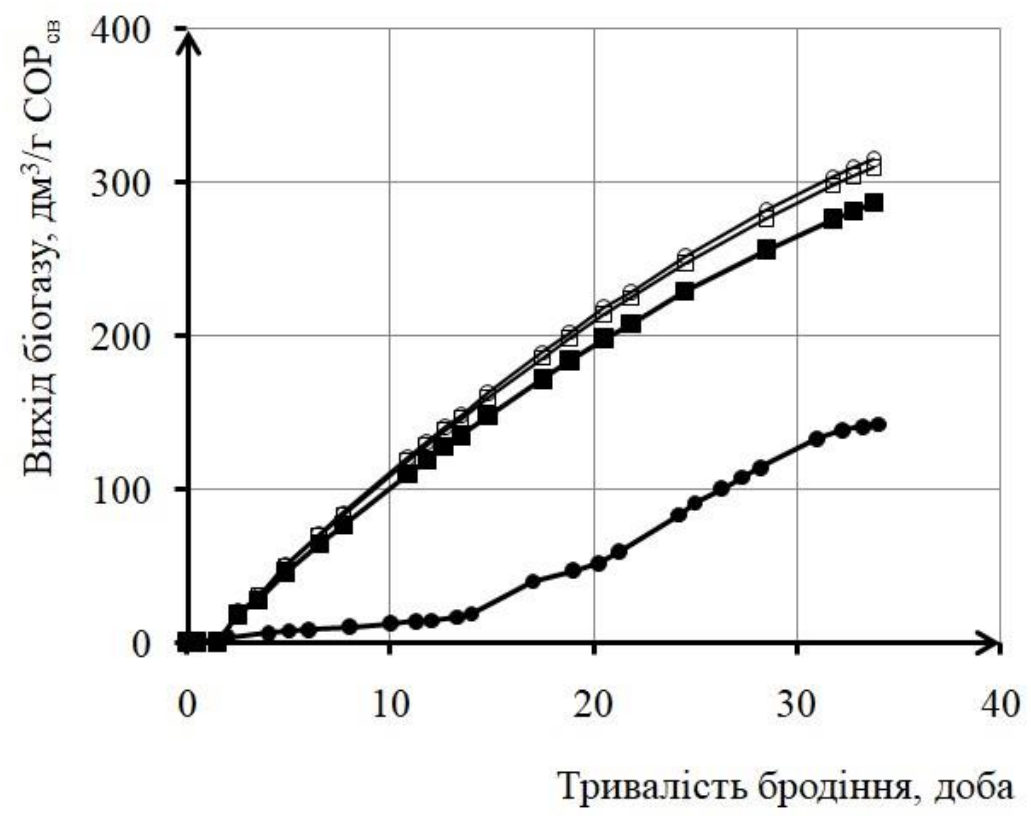

Рис. 1. Вихід біогазу залежно від співвідношення I/C: • - 0; $\square-1$; $\square-2$; $\circ-4$

Fig. 1. Yield of biogas depending on the ratio $I / C: \bullet-0 ; \square-1 ; \square-2 ; \circ-4$

Достовірність одержаних результатів підтверджується тим, що стандартне відхилення акумульованого об’єму метану, одержаного в реакторі 3 досліджуваним субстратом, не перевищує $5 \%$, а також порівнянням 3 результатами інших дослідників за однакових умов зброджування $[2,12]$.

Узагальнивши отримані експериментальні дані, встановили, що кумулятивний вихід біогазу на 34-й день зброджування становив $141,9 \mathrm{~cm}^{3} / \Gamma$ $\mathrm{COP}_{\mathrm{cB}} ; \quad 286,7 \mathrm{~cm}^{3} / \Gamma \quad \mathrm{COP}_{\mathrm{cB}} ; \quad 309,6 \mathrm{~cm}^{3} / \Gamma \quad \mathrm{COP}_{\mathrm{cв}}$ і $315,4 \mathrm{~cm}^{3} / \Gamma \mathrm{COP}_{\text {св }}$ при переробці субстратів, у яких співвідношення I/C було 0; 1; 2 і 4 відповідно.

Склад біогазу був такий: $39,2 \% \mathrm{CO}_{2}$, $58,8 \% \mathrm{CH}_{4} ; 37,5 \% \mathrm{CO}_{2}, 60,5 \% \mathrm{CH}_{4} ; 37,4 \% \mathrm{CO}_{2}$, $60,6 \% \quad \mathrm{CH}_{4} ; \quad 37,6 \% \quad \mathrm{CO}_{2}, \quad 60,4 \% \mathrm{CH}_{4} \quad$ при переробці субстратів, в яких співвідношення I/C було 0; 1; 2 і 4 відповідно.

Ступінь розпаду органічного субстрату був такий: $33,5 \%$; $44 \%$; 44,3\% та 44,4\% при переробці субстратів, в яких співвідношення I/C було 0; 1; 2 і 4 відповідно.

Наведемо умову, за якої значення I/C можна вважати раціональним. Для вибору раціонального значення I/C необхідно, щоб відхилення значення виходу біогазу було незначним до невеликих змін параметру I/C. Кумулятивний вихід біогазу на 34-й день зброджування підвищився на $1,9 \%$ при переробці субстрату 3 I/C $=4$ у порівнянні 3 субстратом, де $\mathrm{I} / \mathrm{C}=2$, на $8 \%$ при переробці субстрату з I/C = 2 у порівнянні з субстратом, де $\mathrm{I} / \mathrm{C}=1$, на $202 \%$ при переробці субстрату 3 $\mathrm{I} / \mathrm{C}=1$ у порівнянні з субстратом, де $\mathrm{I} / \mathrm{C}=0$.

Проаналізувавши кумулятивний вихід біогазу залежно від співвідношення між органічною речовиною інокуляту та субстрату, встановили, що вихід біогазу суттєво нижчий для субстрату, що містив виключно власну клітинну біомасу коров'ячого гною у порівнянні 3 субстратами, які змішувались 3 інокулятом. Для значень I/C, які дорівнюють або вище 1, динаміка виходу біогазу змінилася неістотно. 
Отже, підсумувавши отримані результати проведених експериментів, можна зробити такі висновки: по-перше, інокулят необхідний навіть для тих органічних субстратів, які містять власну клітинну біомасу; по-друге, для органічних субстратів на основі тваринницької біомаси, які містять у своєму складі клітинну біомасу, достатньо, щоб значення I/C було не нижче за 1.

Вибір значення I/C для виконання тесту з визначення метанового потенціалу.

На основі власних експериментальних досліджень було показано, що під час зброджування коров'ячого гною, важливим при виборі значення I/C була наявність клітинної біомаси у вихідному субстраті.

Відомо, що: цукор і крохмаль розщеплюються швидко завдяки простій структурі та вимагають короткого часу перебування у реакторі; целюлоза і геміцелюлоза мають розгалужену структуру, тому розкладаються повільно; лігнін розкладається бактеріями погано. Оскільки вибір величини I/C залежить від інтенсивності процесу зброджування, то при плануванні проведення тесту 3 визначення метанового потенціалу органічних субстратів варто з'ясувати, 3 яких компонентів складаються субстрати. А саме визначити вміст легко- та важкозброджуваних компонентів у вихідному субстраті.

Отже, для виконання тесту 3 визначення метанового потенціалу органічних субстратів необхідно вибирати значення I/C, виходячи 3 наявності власної клітинної біомаси і вмісту легко- та важкозброджуваних компонентів у вихідному субстраті.

Таким чином, наведено два критерії, відносно яких слід виконувати вибір I/C для різних видів органічних субстратів при визначенні їхнього метанового потенціалу: перший критерій - це наявність власної клітинної біомаси у субстраті; другий критерій - це наявність переважно легкозброджуваних компонентів у субстраті.

Розділимо органічні субстрати, які $\epsilon$ перспективними i можуть першочергово бути використані в біогазових станціях, на чотири групи відповідно до наведених критеріїв. В табл. 3 представлено типові органічні субстрати.

Таблиця 3. Типові органічні субстрати

Table 3. Typical organic substrate

\begin{tabular}{|l|c|c|}
\hline & $\begin{array}{c}\text { Переважають у складі } \\
\text { легкозброджувані компоненти }\end{array}$ & $\begin{array}{c}\text { Переважають у складі } \\
\text { важкозброджувані компоненти }\end{array}$ \\
\hline $\begin{array}{l}\text { Містять власну клітинну } \\
\text { біомасу }\end{array}$ & Коров'ячий гній & $\begin{array}{c}\text { Курячий послід, свинячий гній } \\
\text { тощо }\end{array}$ \\
\hline $\begin{array}{l}\text { Не містять власної клітинної } \\
\text { біомаси }\end{array}$ & $\begin{array}{c}\text { Буряковий жом, харчові } \\
\text { відходи тощо }\end{array}$ & Агровідходи \\
\hline
\end{tabular}




\section{Виконаємо}

узагальнення

відомих

результатів щодо вибору I/C для виконання тесту

3 визначення метанового потенціалу для різних

видів органічних субстратів. Проаналізувавши отримані експериментальні результати М. Miax, Ф. Рапосо, Р. Жанг, В. Ванг та Р. Дагує [2, 17-20] для виконання тесту 3 визначення метанового потенціалу органічних субстратів, встановили: для органічних субстратів, які містять власну клітинну біомасу і в складі яких переважають легкозброджувані компоненти, співвідношення $\mathrm{I} / \mathrm{C}=1$; для органічних субстратів, які не містять власної клітинної біомаси та в складі яких переважають важкозброджувані компоненти, співвідношення $\mathrm{I} / \mathrm{C}=4$; в інших випадках співвідношення $\mathrm{I} / \mathrm{C}=2$. Ф. Рапосо рекомендував за наявності у субстраті речовин, що можуть інгібувати процес зброджування, або за умови низького метанового потенціалу органічного субстрату використовувати більшу кількість інокуляту, що забезпечить стабільний перебіг процесу зброджування [17].

Надамо рекомендації щодо вибору значення I/C для тих видів сировини, що $\epsilon$ перспективними i можуть першочергово бути використані в біогазових станціях Рекомендовано взяти такі значення I/C: для коров'ячого гною $-\mathrm{I} / \mathrm{C}=1$; для свинячого гною, курячого посліду, бурякового жому, харчових відходів тощо $-\mathrm{I} / \mathrm{C}=2$, для сумішевих субстратів, що містять рослинну біомасу $\mathrm{I} / \mathrm{C}=4$.

Таким чином, на основі власних експериментальних досліджень та аналізу отриманих результатів інших науковців наведені необхідні значення I/C для різних видів органічних субстратів, які є перспективними i можуть першочергово бути використані в біогазових станціях, що дає змогу визначити їхній метановий потенціал.

\section{Висновки:}

1. Показано, що для проведення тесту 3 визначення метанового потенціалу органічних субстратів, що містять коров'ячий гній, достатньо струшувати вміст реактора вручну раз на добу.

2. Встановлено, що для органічних субстратів на основі тваринної біомаси достатньо, щоб значення I/C було не нижче 1.

3. На основі власних експериментальних досліджень та аналізу отриманих результатів інших науковців наведені необхідні значення I/C для різних видів органічних субстратів, які $\epsilon$ перспективними і можуть першочергово бути використані в біогазових станціях, що дає змогу визначити їхній метановий потенціал.

1. Eshore S., Mondal C., Das A. Production of biogas from treated sugarcane bagasse. International Journal of Scientific Engineering and Technology. 2017. Vol. 6. Iss. 7. Pp. 224-227.

2. Miah M., Rahman A., Kalam A. Production of biogas from poultry litter mixed with the co-substrate cow dung. Journal of Taibah University for Science. 2016. Vol. 10. Iss. 4. Pp. 497-504.

3. Gaworski M., Jablonski S. Enhancing biogas plant production using pig manure and corn silage by adding wheat straw processed with liquid hot water and steam explosion. Biotechnol. Biofuels. 2017. Vol. 10. Pp. 259-271.

4. Angelidaki I., Ahring B. Thermophilic anaerobic digestion of livestock waste: the effect of ammonia. Appl. Microbiol. Biotechnol. 1993. Vol. 38. Pp. 560-564.

5. Lindmark J., Eriksson P., Thorin E. The effects of different mixing intensities during anaerobic digestion of the organic fraction of municipal solid waste. Waste Management. 2014. Vol. 34. Pp. 1391-1397. 
6. Pecorini I, Baldi F, Carnevale E., Corti A. Biochemical methane potential tests of different autoclaved and microwaved lignocellulosic organic fractions of municipal solid waste. Waste Management. 2016. Vol. 56. Pp. 143-150.

7. ISO-11734. Water quality. Evaluation of the "ultimate" anaerobic biodegradability of organic compounds in digested sludge. Method by measurement of the biogas production. Geneva. 1995.

8. ISO-14853. Plastics-Determination of the ultimate anaerobic biodegradation of plastic materials in an aqueous system-Method by measurement of biogas production. London. British Standards Institute. 2005.

9. ASTM-D5210. Standard test method for determining the anaerobic biodegradation of plastic materials in the presence of municipal sewage sludge. West Conshohocken. Pennsylvania. 2007.

10. ASTM-E2710. Standard test method for determining anaerobic biodegradation potential of organic chemicals under methanogenic conditions. West Conshohocken. Pennsylvania. 2008.

11. VDI 4630. Fermentation of organic materials. Characterisation of the substrate, sampling, collection of material data, fermentation tests. Dusseldorf: Verein Deutscher Ingenieure. 2016.

12. Automatical methane potential test system Operation and maintenance manual. Lund. Bioprocess control Sweden AB. 2016.95 p.

13. Четверик Г.О. Енергоефективне перетворення рідких відходів газифікації біомаси в біогазовій установці. Автореф. дис. на здобуття наук. ступеня канд. техн. наук. спец. 05.14.08. К. 2018. 21 с.

14. ДСТУ EN 12048:2005. Добрива тверді та вапнувальні матеріали. Визначення вмісту вологи гравіметричним методом. Висушування за температури $105 \pm 2^{\circ} \mathrm{C}$. К. Держспоживстандарт України. 2006.

15. ГОСТ 26714-85. Удобрения органические. Метод определения золы: М. Гос. комитет СССР по стандартам. 1987.

16. Holliger C., et al. Towards a standardization of biomethane potential tests: a commernaty. Water Science and technology. 2021. Vol. 83. № 1. Pp. 247-250.

17. Raposo F. Biochemical methane potential of solid organic substrates: evaluation of anaerobic biodegradability using data from an international laboratory study. Chem. Technol. Biotechnol. 2011. Vol. 86. Pp. 1088-1098.
18. Wang $B$. Factors that influence the biochemical methane potential (BMP) test steps towards the standardization of bmp test. avtoref. of doctoral dissertation. Lund University. 2020. $48 \mathrm{p}$

19. Zhang R., Hamed M., Hartman K., et al. Characterization of food waste as feedstock for anaerobic digestion. Bioresource Technology. 2007. № 98. Pp. 929-935.

20. Dague R., McKinney R., Pfeffer J. Solids retention in anaerobic waste treatment systems. Journal Water Pollution Control Federation. 1970. Vol. 42. № 2. Pp. 29-46.

\section{REFERENCES}

1. Eshore S., Mondal C., Das A. Production of biogas from treated sugarcane bagasse. International Journal of Scientific Engineering and Technology. 2017. Vol. 6. Iss. 7. Pp. 224-227. [in English].

2. Miah M., Rahman A., Kalam A. Production of biogas from poultry litter mixed with the co-substrate cow dung. Journal of Taibah University for Science. 2016. Vol. 10. Iss. 4. Pp. 497-504. [in English].

3. Gaworski M., Jablonski S. Enhancing biogas plant production using pig manure and corn silage by adding wheat straw processed with liquid hot water and steam explosion. Biotechnol. Biofuels. 2017. Vol. 10. Pp. 259-271. [in English].

4. Angelidaki I., Ahring B. Thermophilic anaerobic digestion of livestock waste: the effect of ammonia. Appl. Microbiol. Biotechnol. 1993. Vol. 38. Pp. 560-564. [in English].

5. Lindmark J., Eriksson P., Thorin E. The effects of different mixing intensities during anaerobic digestion of the organic fraction of municipal solid waste. Waste Management. 2014. Vol. 34. Pp. 1391-1397. [in English].

6. Pecorini I, Baldi F, Carnevale E., Corti A. Biochemical methane potential tests of different autoclaved and microwaved lignocellulosic organic fractions of municipal solid waste. Waste Management. 2016. Vol. 56. Pp. 143-150. [in English].

7. ISO-11734. Water quality. Evaluation of the "ultimate" anaerobic biodegradability of organic compounds in digested sludge. Method by measurement of the biogas production. Geneva. 1995. [in English].

8. ISO-14853. Plastics-Determination of the ultimate anaerobic biodegradation of plastic materials in an aqueous system-Method by measurement of biogas production. London. British Standards Institute. 2005. [in English].

9. ASTM-D5210. Standard test method for determining the anaerobic biodegradation of plastic materials in the presence 
of municipal sewage sludge. West Conshohocken. Pennsylvania. 2007. [in English].

10. ASTM-E2710. Standard test method for determining anaerobic biodegradation potential of organic chemicals under methanogenic conditions. West Conshohocken. Pennsylvania. 2008. [in English].

11. VDI 4630. Fermentation of organic materials Characterisation of the substrate, sampling, collection of material data, fermentation tests. Dusseldorf: Verein Deutscher Ingenieure. 2016. [in English].

12. Automatical methane potential test system. Operation and maintenance manual. Lund. Bioprocess control Sweden AB. 2016. 95 p. [in English].

13. Chetveryk H.O. Energoefektyvne peretvorennia ridkyh vidhodiv hazyfikacii biomasy $\mathrm{v}$ biohazoviy ustanovci. [Energy efficient conversion of liquid waste from biomass gasification in the biogas plant, abstract of the candidate of technical sciences]. Avtoref. dys. na zdobuttya nauk. stupenya kand. tekhn. nauk spets. 05.14.08. K. 2018. 21 p. [in Ukrainian].

14. DSTU EN 12048:2005. Dobryva tverdi ta vapnuval'ni materialy. Vyznachennya vmistu volohy hravimetrychnym metodom. Vysushuvannya za temperatury $105 \pm 2{ }^{\circ} \mathrm{C}$. [State Standard EN 12048:2005. Fertilizers for solid and lime materials. Determination of moisture content by gravimetric method. Drying at $105 \pm 2{ }^{\circ} \mathrm{C}$ ]. State Committee of Ukraine for Technical Regula-tion and Consumer Policy Publ. Kyiv. 2006. [in Ukrainian]
15. GOST 26714-85. Udobreniya organicheskie. Metod opredeleniya zoly. M. Gosudarstvennyy komitet SSSR po standartam, 1987. 8 p. [in Russian].

16. Holliger C., et al. Towards a standardization of biomethane potential tests: a commernaty. Water Science and technology. 2021. Vol. 83. No. 1. Pp. 247-250 [in English].

17. Raposo F. Biochemical methane potential of solid organic substrates: evaluation of anaerobic biodegradability using data from an international laboratory study. Chem. Technol. Biotechnol. 2011. Vol. 86. Pp. 1088-1098. [in English].

18. Wang B. Factors that influence the biochemical methane potential (BMP) test steps towards the standardization of bmp test. avtoref. of doctoral dissertation. Lund University. 2020. 48 p. [in English].

19. Zhang R., Hamed M., Hartman K., et al. Characterization of food waste as feedstock for anaerobic digestion. Bioresource Technology. 2007. No. 98. Pp. 929-935. [in English].

20. Dague R., McKinney R., Pfeffer J. Solids retention in anaerobic waste treatment systems. Journal Water Pollution Control Federation. 1970. Vol. 42. No. 2. Pp. 29-46. [in English]. 